\title{
PORTUGUESE TRANSLATION AND VALIDATION OF THE YQOL - FD (YOUTH QUALITY OF LIFE INSTRUMENT-FACIAL DIFFERENCES) FOR BRAZILIAN ADOLESCENTS WITH CRANIOFACIAL DEFORMITIES
}

\author{
TRADUÇÃO E VALIDAÇÃO EM PORTUGUESS DO YQOL - FD (YOUTH QUALITY \\ OF LIFE INSTRUMENT - FACIAL DIFFERENCES) PARA ADOLESCENTES \\ BRASILEIROS COM DEFORMIDADES CRANIOFACIAIS
}

\author{
Paulo Eduardo DAMIANI ${ }^{1}$; Daniela Yukie Sakai TANIKAWA ${ }^{2}$; \\ Beatriz Silva Câmara MATTOS ${ }^{1}$; Tatiana Borges Saito PAIVA ${ }^{1}$; Marcia ANDRÉ ${ }^{1}$ \\ 1. Department of Maxillofacial Surgery, Prosthodontics, and Traumatology, Dentistry School, University of São Paulo, SP- Brazil; 2. \\ Division of Plastic Surgery, Department of Surgery, School of Medicine, University of São Paulo, SP- Brazil. \\ paulodamiani@usp.br
}

\begin{abstract}
The Youth Quality of Life-Facial Differences (YQOL-FD), validated in the United States in 2005, was developed at the University of Washington by the Seattle Quality of Life Group (SeaQol), to evaluate quality of life of adolescents with facial deformities. Because no Portuguese version exists, the measure was not viable in Brazil. This study aimed to obtain linguistic and psychometric validation of a version of the YQOL-FD in Portuguese. Twenty-five patients with cleft lip and palate and five without facial deformity participated in Traumatology and Maxillofacial Prosthesis Surgery Clinic, School of Dentistry, University of São Paulo. The linguistic validation of the YQOL-FD was carried out by a team consisting of the researcher, as project manager, two native Portuguese-speaking consultants fluent in English, and one native Englishspeaking consultant fluent in Portuguese. After translation and back-translation, a Portuguese version was obtained, which was applied in a pilot test $(\mathrm{n}=10)$; after the final adjustments the Seattle Quality of Life Group approved the official version of the YQOL-FD in Portuguese. To obtain the psychometric validation, we requested the participation of 20 patients with cleft lip and palate who answered the questionnaire twice in a range of 7 to 15 days. The Cronbach's alpha test was applied in the 48-item block, showing a high degree of internal consistency (0.949). The Wilcoxon Signal Post Test was applied to verify if the test and retest values were similar; the general agreement was $4 / 5=80 \%$, indicating high reproducibility. It was concluded that the Portuguese version of the YQOL-FD is adequate for evaluating Quality of Life of Brazilian adolescents with craniofacial deformities.
\end{abstract}

KEYWORDS: Quality of life. Cleft lip. Cleft palate. Cleft lip and palate. Adolescents.

\section{INTRODUCTION}

Quality of life is defined as an individual's perception of his or her position in life in the context of the culture and value system in which they live and in relation to their goals, expectations, standards, and concerns. Adolescents with a facial deformity may experience significant distress, but the ways to better solve this problem remain poorly studied (RIKLIN et al., 2019). It is a broad concept that expresses its subjectivity and multidimensionality and is a window through which one's own perceptions are evaluated (WHOQOL, 1995; BONOMI et al., 2000). Among the main objectives pursued in current clinical trials is the improvement of people's quality of life. In the research into new methodologies for treatment and prevention of diseases, the need to standardize their analysis emerged (NOBRE, 1995).

There are several methodological differences between studies about quality of life assessment among individuals with cleft lip and palate (QUEIROZ HERKRATH et al. 2015). Quality of life assessment during adolescence presents special challenges, including finding the most important and relevant domains, conceptualizing the thoughts and feelings of adolescents and indicating both "positive" and "negative" aspects of their lives, and measuring their self-perception with a valid and reliable instrument (PATRICK et al., 2002). Measuring instruments were needed to assess and compare the quality of life of groups of vulnerable adolescents, such as those with disabilities or special health 
needs, with that of the general adolescent population (PATRICK, 1997).

The use of a standard questionnaire and standardized assessment by a calibrated examiner is an indispensable factor for quality of life research (MONTES et al. 2019). When choosing an assessment instrument, it must be consider whether its components present idiomatic, semantic, cultural, and conceptual equivalents (GUILLEMIN et al., 1993). In the search for an instrument to evaluate the quality of life of adolescents with cleft lip and palate, the most appropriate one we found in the literature was the Youth Quality of Life Instrument_Facial Differences (YQOL-FD), developed by the Seattle Quality of Life Group (SeaQOL), Department of Health Services, University of Washington, which is a questionnaire designed and validated specifically for young patients with craniofacial deformities (EDWARDS et al., 2005). The YQOL-FD consists of 48 items, including questions and statements, related to perceptual and contextual aspects. The first part of the questionnaire contains 18 contextual questions and the second part consists of 30 items distributed in five domains which are: 1) Coping; 2) Negative self image; 3) Positive Consequences; 4) Negative Consequences; 5) Stigma. The YQOL-FD in its original version can be found at: http://www.seaqolgroup.org.

Each society has its own characteristics reflecting the national culture and differentiating it from others. Similarly, health problems are expressed differently across cultures. Thus, when proposing application of a health-related data collection or measurement tool, the criteria proposed in the literature should be observed, resulting in an instrument with simple, clear language and conceptual equivalence (CICONELLI et al., 1999). The process of linguistic validation of an instrument in another language is not a literal translation but the production of a translation that is conceptually equivalent to the original and culturally acceptable in the country where the translation will be used. It requires a systematic approach that takes the following steps: translation, back-translation, and cultural adaptation.

This study aimed to obtain an official version of the YQOL-FD questionnaire in Portuguese and to submit it to psychometric validation.

\section{MATERIAL AND METHODS}

Ethics approval and consent to participate
The procedures in this study were approved by the School of Dentistry Ethics Committee, University of São Paulo, number 835.697 and all patients has signed the consent form.

\section{Linguistic Validation}

The first step was to translate and adapt the YQOL-FD into Portuguese. All internationally accepted standards were met. In addition, the guidance in the Language Validation Manual provided by the developers of the instrument, SeaQOL, were strictly followed.

The Linguistic Validation team indicated in the methodology of the SeaQOL Linguistic Validation Manual was constituted as follows:

1. Project Manager: responsible for overseeing the translation process and mediation to obtain the reconciled version.

2. Consultants 1 and 2: native Portuguese translators, bilingual and fluent in written and spoken English, with notions about the concept of Quality of Life, responsible for translations 1 and 2 and conciliatory translation process.

3. Consultant 3: native English-speaking translator, bilingual and fluent in Portuguese, with notions about the concept of Quality of Life, responsible for the backtranslation of the reconciled version and comparison with the original version.

With the translation team already formed, we started the validation process.

\section{Phase I: Direct translation}

This phase can be summarized as the first pass from the original language (English) to the target language (Portuguese) by Consultants 1 and 2. Each translator independently produced an initial version. Then, comparing the two versions, we chose the best translation for each item to obtain the reconciled version. Thus, we obtained Version 1 in Portuguese.

\section{Phase II: Back-translation}

At this stage, Consultant 3, a native English language speaker, back-translated Version 1 into English. The researcher, as Project Manager, assisted by Consultant 3, compared the backtranslation with the original version of the YQOLFD. All doubts were clarified regarding possible inaccuracies or even errors in translation as well as understanding, and the necessary corrections and modifications were made, leading to Version 2. 
The "Translation Table" in the Linguistic Validation Manual provided by the developer was completed by the work team, including item-byitem discussion in detail. At present, a report has been drawn up presenting the consultants' qualifications and comments. This material (Table and Report) has been submitted to the YQOL-FD development team for review and approval of this release.

\section{Phase III: Cognitive analysis}

Cognitive analysis is necessary to know if the translated version of the questionnaire is acceptable and easy to understand as well as if the language used is simple and appropriate for the population in which the questionnaire will be applied. Version 2 of the questionnaire was obtained after Phase II was applied in a "Pilot Test" with 10 participants between the ages of 14 and 18 years, 5 of whom had complete cleft lip and palate and 5 of whom had no facial deformity. The test was applied as an interview, during which participants were asked about any difficulty with understanding and problems with interpreting items addressed in the instrument; when necessary, alternative proposals for translation were suggested.

A report of the interviews was produced containing the number of participants, their ages, the time taken to complete the questionnaire, the difficulties encountered, and the solutions proposed. Finally, a third version of the questionnaire was produced. This version, called Version 3, was sent with this second report to the YQOL-FD development team for review and approval. After some minor adaptations and suggestions from the Seattle team, the official version of the YQOL-FD in Portuguese was approved. Total validation process was completed in 6 months.

\section{YQOL-FD Psychometric Validation (Portuguese Version)}

For this stage, 20 patients were selected from the Cleft Lip and Palate Outpatient Clinic of the Department of Maxillofacial Surgery, Prosthodontics and Traumatology, Dentistry School University of São Paulo. These patients with cleft lip and palate, had already undergone primary repair surgeries, were in the age range of 11 to 18 years, and were of both genders regardless of ethnicity. Prior to questionnaire application, all participants received guidance on the research purpose and notions about quality of life through a small explanatory speech. The adolescents were accommodated comfortably in an appropriate place and without distractions that could disrupt or interrupt responses. The 20 participants were asked to return in 7-15 days to respond again to the same questionnaire to compare the answers and, thus, test the reliability and reproducibility of the official Portuguese version of the YQOL-FD. Data from the 40 completed questionnaires were placed in the spreadsheet and then submitted to statistical analysis. The Cronbach's Alpha Statistical Test was used to verify the level of reliability in terms of the so-called "internal consistency" of the observed values. The Wilcoxon Signpost Test was used to verify that test and retest values are similar.

The complete sequence of the linguistic validation steps is presented in Figure 1 (GOES et al., 2013) to illustrate the process.

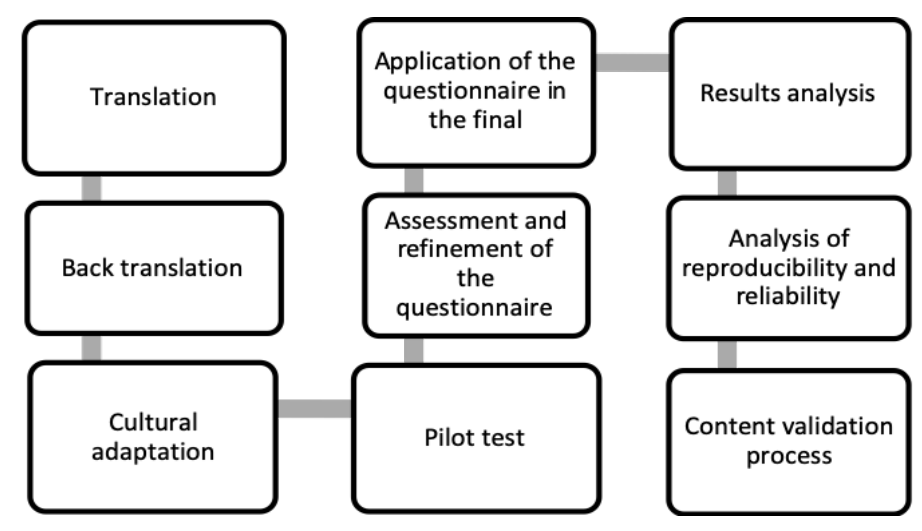

Figure 1. Validation scheme of a data collection instrument for another language.

\section{RESULTS}

For the psychometric validation, the sample profile can be seen in table 1 , which presents the group of 20 patients with cleft lip and palate who responded to the test and retest to evaluate the reliability and reproducibility of the Portuguese version. of the YQOL-FD. 
Table 1. Distribution of the sample of adolescents with cleft according to type of cleft, gender, and age group $(n=20)$.

\begin{tabular}{|c|c|c|c|c|c|c|c|c|c|c|c|c|c|c|}
\hline \multirow{3}{*}{$\begin{array}{c}11 \text { a } 14 \\
\text { yo }\end{array}$} & \multicolumn{6}{|c|}{ Male } & \multicolumn{6}{|c|}{ Female } & \multirow{2}{*}{\multicolumn{2}{|c|}{ Total }} \\
\hline & \multicolumn{2}{|c|}{ Cleft/rigth } & \multicolumn{2}{|c|}{ Cleft/left } & \multicolumn{2}{|c|}{ Cleft /bi } & \multicolumn{2}{|c|}{ Cleft/rigth } & \multicolumn{2}{|c|}{ Cleft/left } & \multicolumn{2}{|c|}{ Cleft /bi } & & \\
\hline & 1 & $(5 \%)$ & 5 & $(25 \%)$ & 4 & $(20 \%)$ & 1 & $(5 \%)$ & 1 & $(5 \%)$ & 2 & $(10 \%)$ & 14 & $(70 \%)$ \\
\hline $\begin{array}{c}15 \text { a } 18 \\
\text { yo }\end{array}$ & 0 & $(0 \%)$ & 1 & $(5 \%)$ & 0 & $(0 \%)$ & 0 & $(0 \%)$ & 4 & $(20 \%)$ & 1 & $(5 \%)$ & 6 & $(30 \%)$ \\
\hline Total & 1 & $(5 \%)$ & 6 & $(30 \%)$ & 4 & $(20 \%)$ & 1 & $(5 \%)$ & 5 & $(25 \%)$ & 3 & $(15 \%)$ & 20 & $(100 \%)$ \\
\hline
\end{tabular}

Table 2 presents the Cronbach's alpha results for the 48 questions of the YQOL-FD, showing a high degree of internal consistency
(0.949), indicating this study uses a non-biased sample.

Table 2. Cronbach's alpha test of internal consistency of the YQOL-FD.

\begin{tabular}{ccc}
\hline Aspect & Cronbach's Alpha & Statistical significance \\
\hline 48 questions & 0.949 & $<0.001$ \\
\hline
\end{tabular}

The Wilcoxon Signpost Test (Table 3) was used to verify that test and retest values are similar $(p>0.050)$. Four of the five domains present "concordance" (similarity between the two moments of observation). Therefore, the general agreement is $4 / 5=0.8=80 \%$ for the domains.

Table 3. Wilcoxon test to verify differences between domains.

\begin{tabular}{cccccccccc}
\hline Subitems & $\mathrm{n}$ & Average & SD & Mínimum & Maximum Percentil & 25 Percentile 50 (Median) Percentile & 75 Sig. $(\mathrm{p})$ \\
\hline [t] coping & 20 & 53.00 & 34.72 & 0.00 & 100.00 & 15.00 & 57.50 & 86.25 & 0.008 \\
[rt] coping & 20 & 46.13 & 33.83 & 0.00 & 100.00 & 10.63 & 51.25 & 74.38 & \\
[t] negself & 20 & 11.75 & 18.29 & 0,00 & 63.33 & 0.00 & 1.67 & 16.25 & 0.580 \\
[rt] negself & 20 & 12.25 & 18.55 & 0.00 & 56.67 & 0.00 & 3.33 & 18.33 & \\
[t] poscon & 20 & 54.80 & 28.89 & 0.00 & 100.00 & 37.00 & 58.00 & 79.50 & 0.169 \\
[rt] poscon & 20 & 50.80 & 29.77 & 0.00 & 96.00 & 30.00 & 53.00 & 73.00 & \\
[t] negcon & 20 & 22.70 & 22.19 & 0.00 & 78.00 & 3.00 & 17.00 & 37.00 & 0.132 \\
[rt] negcon & 20 & 25.20 & 26.77 & 0.00 & 88.00 & 2.00 & 18.00 & 42.00 & \\
[t] stigma & 20 & 23.40 & 25.36 & 0.00 & 77.00 & 3.50 & 14.50 & 33.75 & 0.394 \\
[rt] stigma & 20 & 22.15 & 25.23 & 0.00 & 84.00 & 2.00 & 10.00 & 39.50 & \\
\hline
\end{tabular}

$\mathrm{t}=$ test, $\mathrm{rt}=$ retest; $\mathrm{n}=$ number of patients; negself $=$ negative self image; poscon= positive consequences; negcon= negative consequences

\section{DISCUSSION}

There is virtually universal consensus on the evaluation of the quality of life in individuals with facial deformities as a means of assessing the efficacy of a therapeutic protocol (PATRICK et al., 2007; RAPOSO DO AMARAL et al., 2011; KLASSEN et al., 2012). Quality of life is measured using general or specific health questionnaires for specific pathologies, but they are almost always developed in the English language, and their use in countries with other languages requires rigorous translation and revalidation.

KORTELAINEN et al. (2016), conducted a comparative study for validation of the Child Perception Questionnaire (CPQ11-14), and concluded that the oral health-related quality of life of Finnish children with CLP was considerably poorer than that of their peers in all dimensions, especially social welfare. 
It is important to emphasize that there is a significant number of protocols proposed by different reference centers for the rehabilitation of patients with craniofacial deformities, particularly those with orofacial clefts. Although a standard treatment is established, the quality of life of these patients and their families is affected (ZERAATKAR et al., 2018). The presence of cleft lip and/or palate negatively affected the healthrelated quality of life, mainly on psychosocial dimensions (QUEIROZ HERKRATH et al., 2015).

In making this review, it was difficult to find really effective instruments to measure the quality of life of individuals with craniofacial deformities. Many questionnaires were created and transcribed in different publications, and, although their diversity is significant, it was very difficult to find one that comprehensively covers orofacial clefts. KLASSEN et al. (2012) identified 28 different questionnaires applied to measure the results from the perspective of the patients or their parents; however, almost all of these instruments were used only once.

The YQOL-FD, instrument developed at the Department of Health Services of the University of Washington (PATRICK et al., 2007) it was the most appropriate for application in patients with cleft lip and palate because items were dedicated exclusively to facial deformities, and, since it has elements specifically designed for adolescents and young adults, it can allow a relevant study of the treatment protocol used; in this age group, they are in the final stage of rehabilitation.

To obtain linguistic validation of the YQOL-FD for Portuguese, patients with clefts were selected in the metropolitan region of São Paulo that had equivalent socioeconomic and cultural levels. Brazil is a country with an extensive territorial area with significant cultural and social diversity, but this does not characterize a bias of this work, whose objective was to seek a language that was faithful to the original.

When selecting the sample, decided that patients with isolated clefts of the palate would not be interviewed because they did not present facial differences, and the YQOL-FD instrument has as weak point of not considering functional alterations such as speech, voice quality, hearing, and chewing (RAPOSO DO AMARAL et al., 2011; ECKSTEIN et al., 2011). However, Klassen et al. (2012) emphasize that the YQOL-FD instrument was developed to study the quality of life of adolescents with a wide range of craniofacial malformations and not to cover the specific problems of the population with cleft lip and palate.
It was decided not to include the isolated clefts of the lip because they are the least severe, and many patients with cleft lip have almost imperceptible scars, which could also intervene in the domain scores and constitute a bias of this work.

The validation process was not easy and required a significant amount of time to complete, which can be seen in the description of the methodology. For linguistic validation, difficulties were observed in understanding some items; these were responsible for small changes in the text to facilitate participants' understanding. For example, the question "How often do you have your picture taken?" has been replaced with "How often do you take photos that you appear in?".

After the Portuguese version was accepted by the developers of the YQOL-FD, and to complement the validation process, this study aimed to evaluate the reliability and reproducibility of the instrument in its different domains.

The statistical tests showed results similar to those found by PATRICK et al. (2007). The Cronbach's alpha test for internal consistency of the YQOL-FD, whose results are shown in Table 2, presented the coefficient of 0.949 , which surpasses that presented in the reference study, demonstrating high consistency since it exceeds 0.70 . The same occurred in the reproducibility test, which presented, in the individual item evaluation, 93.73\% agreement between test and retest behaviors, and, when grouped in domains, the value was $80 \%$ (Table 3 ), showing high reproducibility, it can be consider high concordances when this ratio is above $2 / 3$ $(66.67 \%)$. For the YQOL-FD (english version), the Cronbach alpha test and I.C.C (Intraclass correlation coefficient) were used., applied within the five domains and presented results as follow: 1). Cronbach's Alpha: between 71\% and 90\%; 2). I.C.C.: between $80 \%$ and 91\% (PATRICK et al. 2007).

Adolescence is a phase where facial appearance and attractiveness are very important for self-esteem and psychosocial well-being, which is why this instrument is considered very valuable, however for small cleft lip and palate rehabilitation centers this instrument ends up being limiting in obtaining a significant sample, as it excludes patients outside this age group.

Positive data provided by psychometric validation encourage the application of this instrument in a larger sample within reference centers for rehabilitation of patients with cleft lip and palate and thus contribute to the improvement of their quality of life. 


\section{CONCLUSION}

The Portuguese version of the YQOL-FD, adapted to the Brazilian language and culture, was presented in simple language, which can be understood by young Brazilians of any sociocultural level in the age group from 11 to 18 years old with some type of craniofacial deformity, either congenital or acquired.

RESUMO: O YQOL-FD (Youth Quality of Life - Facial Differences) validado nos EUA em 2005, foi desenvolvido na Universidade de Washington, pelo Seattle Qualitity of Life Group (SeaQol), com a finalidade de avaliar a qualidade de vida de adolescentes com deformidades faciais. Por não apresentar uma versão no idioma português o seu uso não poderia ser viabilizado no Brasil. O objetivo deste trabalho foi conseguir a validação linguística e a validação psicométrica de uma versão do YQOL-FD, no idioma português do Brasil. Participaram deste estudo 25 pacientes com Fissura de Lábio e Palato (FLP) e 5 sem qualquer deformidade facial, em atendimento na Clínica do Departamento de Cirurgia Traumatologia e Prótese Maxilofacial da Faculdade de Odontologia da Universidade de São Paulo. A validação linguística do YQOL-FD foi realizada por uma equipe constituída pelo pesquisador, como gerente de projeto, por 2 consultores nativos da língua portuguesa muito fluentes em inglês e por 1 consultor nativo de língua inglesa com fluência em português. Após a tradução e a retrotradução obteve-se uma versão em português, a qual foi aplicada em um teste piloto, com $\mathrm{n}=10$, sendo 5 adolescentes com FLP e 5 sem FLP, que após os acertos finais permitiu que o SeaQol aprovasse a versão oficial do YQOL - FD em português. Para a obtenção da validação psicométrica solicitouse a participação de 20 pacientes com FLP que responderam ao questionário por 2 vezes em um intervalo de 7 a 15 dias. O teste de Cronbach foi aplicado no bloco de 48 itens mostrando alto grau de consistência interna $(0,949)$. Na aplicação do Teste dos Postos Sinalizados de Wilcoxon, com o intuito de verificar se os valores do teste $(\mathrm{t})$ e do re-teste (rt) são semelhantes, foi possível observar que a concordância geral é de $4 / 5=80 \%$, portanto uma reprodutibilidade elevada. Concluiu-se que o YQOL-FD na versão em português pode ser utilizado como instrumento adequado para a avaliação da Qualidade de Vida dos adolescentes brasileiros com deformidade carniofacial.

PALAVRAS CHAVES: Qualidade de vida. Fissura de lábio. Fissura de palato. Fissura de lábio e palato. Adolescentes.

\section{REFERENCES}

BONOMI AE, PATRICK DL, BUSHNELL DM, MARTIN M. Validation of the United States' version of the World Health Organization Quality of Life (WHOQOL) instrument. J Clin Epidemiol. 2000; 53(1):1-12. https://doi.org/10.1016/S0895-4356(99)00123-7

CICONELLI RM, FERRAZ MB, SANTOS W, MEINÃO I, QUARESMA MR. Tradução para a língua portuguesa e validação do questionário genérico de avaliação de qualidade de vida SF-36 (Brasil SF-36). Rev Bras Reumatol. 1999; 39(3):143-150.

ECKSTEIN DA, WU RL, AKINBIYI T, SILVER L, TAUB PJ. Measuring quality of life in cleft lip and palate patients: currently available patient-reported outcomes measures. Plast Reconstr Surg. 2011; 128(5):518e-26e. https://doi.org/10.1097/PRS.0b013e31822b6a67

EDWARDS TC, PATRICK DL, TOPOLSKI TD, ASPINALL CL, MOURADIAN WE, SPELTZ ML. Aproaches to craniofacial-specific quality of life assessment in adolescents. Cleft Palate Craniofac J. 2005; 42(1): 19-24. https://doi.org/10.1597/03-097.2.1

GOES PSA, FERNANDES LMA, LUCENA LBS, KUSMA S, MOYSES ST, MOYSES SJ. Desenvolvimento e validação de instrumentos de coleta de dados. In: Antunes JLF, Peres MA, editors. Epidemiologia da Saúde Bucal. 2nd ed. São Paulo; 2013, p. 629-45. 
GUILLEMIN F, BOMBARDIER C, BEATON D. Cross-cultural adaptation of health-related quality of life measures: literature review and proposed guidelines. J Clin Epidemiol. 1993;46(12):1417-32.

https://doi.org/10.1016/0895-4356(93)90142-N

KLASSEN AF, TSANGARIS E, FORREST CR, WONG KW, PUSIC AL, CANO SJ, SYED I, DUA M, KAINTH S, JOHNSON J, GOODACRE T. Quality of life of children treated for cleft lip and/or palate: a systematic review . J Plast Reconstr Aesthet Surg. 2012;65(5):547-57.

https://doi.org/10.1016/j.bjps.2011.11.004

KORTELAINEN T, TOLVANEN M, LUOTO A, YLIKONTIOLA LP, SA'NDOR GK, LAHTI S.

Comparison of Oral Health-Related Quality of Life Among Schoolchildren With and Without Cleft Lip and/or Palate . Cleft Palate-Craniofac J; 2016 53(5) pp. e172-e176. https://doi.org/10.1597/14-180

MONTES ABM, OLIVEIRA TM, GAVIÃO MBD, BARBOSA TS. Orofacial functions and quality of life in children with unilateral cleft lip and palate. Braz. oral res. 2019; 33. https://doi.org/10.1590/1807-3107bor2019.vol33.0061

NOBRE MR. Qualidade de vida. Arq Bras Cardiol. 1995; 64(4):299-300.

PATRICK DL. Quality of life: three words with many meanings. Wash Public Health. 1997;15:1-7. https://doi.org/10.1006/jado.2002.0471

PATRICK DL, EDWARDS TC, TOPOLSKI TD. Adolescent quality of life, part II: initial validation of a new instrument. J Adolesc. 2002; 25(3):287-300.

PATRICK DL, TOPOLSKI TD, EDWARDS TC, ASPINALL CL, KAPP-SIMON KA, RUMSEY NJ, STRAUSS RP, THOMAS CR. Measuring the quality of life of youth with facial differences. Cleft Palate Craniofac J. 2007;44(5):538-47. https://doi.org/10.1597/06-072.1

QUEIROZ HERKRATH APC, HERKRATH FJ, REBELO MAB, VETTORE MV. Measurement of HealthRelated and Oral Health-Related Quality of Life Among Individuals With Nonsyndromic Orofacial Clefts: A Systematic Review and Meta-Analysis. Cleft Palate-Craniofac J. 2015; 52(2) pp. 157-172. https://doi.org/10.1597/13-104

RAPOSO DO AMARAL CER, KUCZYNSKI E, ALONSO N. Quality of life among children with cleft lips and palates: a critical review of measurement instruments. Ver Bras Cir Plást. 2011;26(4):639-44. https://doi.org/10.1590/S1983-51752011000400017

RIKLIN E, CALANDRILLO D, BLITZ A, ZUCKERBERG D, ANNUNZIATO RA. Examining the Psychosocial Needs of Adolescents With Craniofacial Conditions: A Mixed-Methods Approach. Cleft Palate Craniofac J. 2019 Sep 12:1055665619870621. https://doi.org/10.1177/1055665619870621

WORLD HEALTH ORGANIZATION QUALITY OF LIFE GROUP. The World Health Organization Quality of Life Assessment (WHOQOL): position paper from the World Health Organization. Soc Sci Med. 1995; 41:1403-9. https://doi.org/10.1016/0277-9536(95)00112-K

ZERAATKAR M, AJAMI S, NADJMI N, GOLKARI A. Impact of Oral Clefts on the Oral Health-Related quality of Life of Preschool Children and their Parents. Nigerian Journal of Clinical Practice; 2018; Vol 21; Issue 9; 1159-1163. 